\title{
Representing nighttime and minimum conductance in CLM4.5: global hydrology and carbon sensitivity analysis using observational constraints
}

\author{
Danica L. Lombardozzi ${ }^{1}$, Melanie J. B. Zeppel ${ }^{2}$, Rosie A. Fisher ${ }^{1}$, and Ahmed Tawfik ${ }^{1,3}$ \\ ${ }^{1}$ National Center for Atmospheric Research, Boulder, CO, USA \\ ${ }^{2}$ Department of Biological Sciences, Macquarie University, Sydney, Australia \\ ${ }^{3}$ Center for Ocean-Land-Atmosphere Studies, George Mason University, Fairfax, VA, USA \\ Correspondence to: Danica L. Lombardozzi (dll@ucar.edu)
}

Received: 31 October 2015 - Published in Geosci. Model Dev. Discuss.: 4 December 2015

Revised: 18 October 2016 - Accepted: 19 December 2016 - Published: 23 January 2017

\begin{abstract}
The terrestrial biosphere regulates climate through carbon, water, and energy exchanges with the atmosphere. Land-surface models estimate plant transpiration, which is actively regulated by stomatal pores, and provide projections essential for understanding Earth's carbon and water resources. Empirical evidence from 204 species suggests that significant amounts of water are lost through leaves at night, though land-surface models typically reduce stomatal conductance to nearly zero at night. Here, we test the sensitivity of carbon and water budgets in a global land-surface model, the Community Land Model (CLM) version 4.5, to three different methods of incorporating observed nighttime stomatal conductance values. We find that our modifications increase transpiration by up to $5 \%$ globally, reduce modeled available soil moisture by up to $50 \%$ in semi-arid regions, and increase the importance of the land surface in modulating energy fluxes. Carbon gain declines by up to $\sim 4 \%$ globally and $>25 \%$ in semi-arid regions. We advocate for realistic constraints of minimum stomatal conductance in future climate simulations, and widespread field observations to improve parameterizations.
\end{abstract}

\section{Introduction}

Terrestrial plants must balance their need to obtain $\mathrm{CO}_{2}$ with the risk of desiccation if transpiration continues unchecked. Higher plants evolved stomatal pores to control the exchange of water and carbon between the leaf interior and the atmo- sphere (Hetherington and Woodward, 2003). Stomatal function is thus the dominant control over terrestrial fluxes of water and carbon. Most large-scale land-surface models use an empirical representation of stomatal conductance $\left(g_{\mathrm{s}}\right)$, similar to the Ball-Woodrow-Berry (BWB) model (Ball, 1988; Ball et al., 1987; Collatz et al., 1991; Leuning, 1995; Medlyn et al., 2011; Sellers et al., 1996), to calculate plant-gas exchange. The BWB model is linear, with two constants, the intercept $\left(g_{o}\right)$ and slope $\left(g_{1}\right)$, and it estimates $g_{\mathrm{s}}$ from the rate of $\mathrm{CO}_{2}$ assimilation $(A)$, atmospheric humidity $\left(h_{r}\right)$, and internal leaf $\mathrm{CO}_{2}$ concentration. The original BWB model parameters were fitted to observations of leaf-gas exchange for 10 plant species, with different $g_{o}$ values for each species, ranging from -310 to $130 \mathrm{mmol} \mathrm{m}^{-2} \mathrm{~s}^{-1}$ (Ball, 1988). The Community Land Model (CLM), however, uses only two $g_{o}$ values, $\left(10\right.$ and $40 \mathrm{mmol} \mathrm{m}^{-2} \mathrm{~s}^{-1}$ for $\mathrm{C}_{3}$ plants and $\mathrm{C}_{4}$ plants, respectively; Collatz et al., 1991; Oleson et al., 2013; Sellers et al., 1996). Conductance during the night (and at other times when $A$ is 0 ) is thus represented using $g_{o}$. Recent advances in our ability to observe nighttime stomatal conductance (Caird et al., 2007; Phillips et al., 2010), $g_{\mathrm{s}, \mathrm{n}}$, illustrate that values are often larger in the field than the BWB parameters used in the CLM.

A comprehensive database (see Table S1 in the Supplement) of 204 observed $g_{\mathrm{s}, \mathrm{n}}$ values illustrates that the minimum BWB $g_{\mathrm{s}}$ values (equivalent to $g_{o}$ ) used in the CLM differ starkly from observed mean and median $g_{\mathrm{s}, \mathrm{n}}$ values. The available data for $g_{\mathrm{s}, \mathrm{n}}$ range from 0 to $450 \mathrm{mmol} \mathrm{m}^{-2} \mathrm{~s}^{-1}$ with an overall mean of $78 \mathrm{mmol} \mathrm{m}^{-2} \mathrm{~s}^{-1}$ (excluding hemiparasites and CAM plants, which were omitted from 
Table 1. Old and new minimum stomatal conductance values used in CLM4.5SP. Units are $\mathrm{mmol} \mathrm{m}^{-2} \mathrm{~s}^{-1}$.

\begin{tabular}{lrrrrr}
\hline Plant functional type & $\begin{array}{r}\text { Old } \\
\text { value }\end{array}$ & $\begin{array}{r}\text { Mean new } \\
\text { value }\end{array}$ & $\begin{array}{r}\text { Median new } \\
\text { value }\end{array}$ & $\begin{array}{r}\text { Standard } \\
\text { deviation }\end{array}$ & $n$ \\
\hline temperate needle-leaf evergreen tree & 10 & 16.896 & 10 & 20.803 & 12 \\
boreal needle-leaf evergreen tree & 10 & 8 & 8 & $\mathrm{n} / \mathrm{a}$ & 1 \\
needle-leaf deciduous tree & 10 & 35.367 & 35 & 6.458 & 3 \\
tropical broadleaf evergreen tree & 10 & 90.488 & 75.5 & 67.850 & 8 \\
temperate broadleaf evergreen tree & 10 & 34.017 & 27 & 28.263 & 25 \\
tropical broadleaf deciduous tree & 10 & 129 & 129 & 41.012 & 2 \\
temperate broadleaf deciduous tree & 10 & 72.637 & 41.66 & 83.525 & 22 \\
boreal broadleaf deciduous tree & 10 & 50 & 50 & $\mathrm{n} / \mathrm{a}$ & 1 \\
broadleaf evergreen shrub & 10 & 65.353 & 29 & 116.062 & 16 \\
broadleaf deciduous shrub & 10 & 129.644 & 60 & 145.539 & 9 \\
c3 grass & 10 & 157.988 & 161 & 67.317 & 24 \\
C4 grass & 40 & 93.933 & 48.5 & 125.533 & 6 \\
crop & 10 & 60.629 & 36.7 & 60.745 & 21 \\
\hline
\end{tabular}

* New values, standard deviation, and $n$ are based on data pooled from the literature. n/a - not applicable

model testing). Observations of $g_{\mathrm{s}, \mathrm{n}}$ are, on average, 10 times higher in broadleaf tropical deciduous species (Table $1 ; 129 \mathrm{mmol} \mathrm{m}^{-2} \mathrm{~s}^{-1}$ ) and 7 times higher in temperate broadleaf deciduous trees $\left(73 \mathrm{mmol} \mathrm{m}^{-2} \mathrm{~s}^{-1}\right)$ compared to the $10 \mathrm{mmol} \mathrm{m}^{-2} \mathrm{~s}^{-1}$ used for $\mathrm{C}_{3}$ plants. Potential benefits of a high $g_{\mathrm{s}, \mathrm{n}}$ might include the transport of nutrients (de Dios et al., 2013; Scholz et al., 2007; Zeppel et al., 2014) or processes related to embolism repair, phloem transport, or xylem refilling that might improve carbon gain, but these ideas remain untested. Nonetheless, the discrepancy between parameterized $g_{o}$ and observed $g_{\mathrm{s}, \mathrm{n}}$ serves as motivation to investigate the sensitivity of simulated landsurface processes to more realistic minimum $g_{\mathrm{s}}$ values. Such field measurements of $g_{\mathrm{s}, \mathrm{n}}$ have not previously been incorporated into a global land-surface model, despite the possible impacts on surface hydrology, ecosystem carbon gain, and land-atmosphere feedbacks.

We use a global land-surface model, the Community Land Model (CLM) version 4.5, forced with a data atmosphere and driven with observed ("satellite phenology") leaf area indices (CLM4.5SP), to test the sensitivity of the land surface to using realistic minimum $g_{\mathrm{s}}$ from observed $g_{\mathrm{s}, \mathrm{n}}$, averaged by plant functional type (PFT; Table 1). Since the BWB approach is primarily intended to predict daytime stomatal behavior, the appropriate method for application of observed $g_{\mathrm{s}, \mathrm{n}}$ within the context of the BWB model is unclear. We therefore test three methodologies for implementing observed $g_{\mathrm{s}, \mathrm{n}}$ : (1) modifying the BWB intercept $\left(g_{o}\right)$, (2) setting a nighttime threshold value, and (3) setting a minimum threshold value. We anticipate that implementing observed $g_{\mathrm{s}, \mathrm{n}}$ values will increase plant transpiration, altering carbon and water budgets on regional and global scales.

\section{Methods}

\subsection{Model description and simulation design}

The CLM4.5SP model used here is an updated version of CLM4.0, originally described by Lawrence et al. (2011), with updated technical details for v4.5 described by Oleson et al. (2013). The CLM4.5SP simulations were run with CRU-NCEP climate forcing data, which combines Climate Research Unit (CRU) TS 3.2 monthly climatology with National Oceanic and Atmospheric Administration National Center for Environmental Prediction (NCEP) and NCAR $2.5^{\circ} \times 2.5^{\circ}$ 6-hourly reanalysis (downloaded at: http://dods.ipsl.jussieu.fr/igcmg/IGCM/BC/OOL/ OL/CRU-NCEP/). This is a historical atmospheric dataset that includes observed precipitation, temperature, downward solar radiation, surface wind speed, specific humidity, and air pressure from 1901 through 2010, and did not include the influences of nitrogen deposition, land-use change, or changing $\mathrm{CO}_{2}$ concentrations.

The CLM4.5SP uses the coupled Farquhar photosynthesis and BWB $g_{\mathrm{s}}$ models to simulate plant physiology (Bonan et al., 2011; Oleson et al., 2013). The BWB $g_{\mathrm{s}}$ is calculated based on the following equation:

$g_{\mathrm{s}}=g_{0} \times \beta_{\text {soil }}+g_{1}\left(A h_{\mathrm{r}} / C_{\mathrm{a}}\right)$,

where $g_{0}$ and $g_{1}$ are empirical fitting parameters of the minimum $g_{\mathrm{s}}$ and the slope of the conductance-photosynthesis relationship, respectively, $A$ is net carbon assimilation rate $\left(\mu \mathrm{mol} \mathrm{C} \mathrm{m}^{-2} \mathrm{~s}^{-1}\right), h_{r}$ is the fractional humidity at the leaf surface (dimensionless), $C_{\mathrm{a}}$ is the $\mathrm{CO}_{2}$ concentration at the leaf surface $\left(\mu \mathrm{mol} \mathrm{mol}^{-1}\right)$, and $\beta_{\text {soil }}$ is the soil wetness scalar, ranging from zero to one (see Oleson et al., 2013). $\beta_{\text {soil }}$ is 
calculated as follows:

$\beta_{\text {soil }}=\Sigma_{i} w_{i} r_{i}$

where $w_{i}$ is a plant wilting factor for layer $i$ and $r_{i}$ is the fraction of roots in layer $i$. When implemented in the unmodified CLM4.5SP, $g_{0}$ is $10 \mathrm{mmol} \mathrm{m}^{-2} \mathrm{~s}^{-1}$ for all $\mathrm{C}_{3}$ plants and $40 \mathrm{mmol} \mathrm{m}^{-2} \mathrm{~s}^{-1}$ for all $\mathrm{C}_{4}$ plants, and is adjusted by $\beta_{\text {soil }}$ (varying from 0 to 1 ) at every time step. It is also important to note that $\beta_{\text {soil }}$ is also applied to the $V_{\mathrm{c}, \max }$ (the maximum rate of carboxylation) parameter in the $A$ equation, as well as to leaf maintenance respiration (Oleson et al., 2013).

Values of $g_{\mathrm{s}, \mathrm{n}}$ based on literature data (Table S1 in the Supplement) are typically larger than the $g_{0}$ values used in current implementations of the BWB model. The $g_{\mathrm{s}, \mathrm{n}}$ data, grouped and then averaged by PFT (Table 1), were used to modify simulated minimum $g_{\mathrm{s}}$ using three methodologies. First, the " $\Delta g_{0}$ " method replaced the BWB minimum conductance, $g_{0}$, value for each PFT with the observed $g_{\mathrm{s}, \mathrm{n}}$ (Table 1), resulting in a uniform increase to $g_{\mathrm{s}}$ during both day and night (referred to as the $\Delta g_{o}$ simulation; method tested previously by Barnard and Bauerle, 2013). Second, the $\Delta g_{\text {night }}$ method implemented the BWB model in its standard form (Eq. 1; the $g_{o}$ and $g_{1}$ values are the same as the control), but included a minimum threshold that was applied only at night, based on observed $g_{\mathrm{s}, \mathrm{n}}$ for each PFT, below which $g_{\mathrm{s}}$ could not fall. In the $\Delta g_{\text {night }}$ simulation, daytime $\Delta g_{\text {s }}$ occasionally fell below the observed nighttime threshold on account of high vapor pressure deficit (VPD) or low assimilation rates. To avoid this potentially unrealistic behavior, we use a third method, " $\Delta g_{\text {min }}$ ", which extended the observation-based threshold used in the $\Delta g_{\text {night }}$ simulation to all times during the day or night, so that $g_{\mathrm{s}}$ never fell below the minimum threshold value found in Table 1 . These three modified simulations were compared to a control simulation using the unmodified BWB formulation. Similar to the unmodified and $\Delta g_{o}$ simulations that adjust the $g_{o}$ parameter based on a soil wetness scalar $\left(\beta_{\text {soil }}\right)$, the $\Delta g_{\text {night }}$ and $\Delta g_{\min }$ modifications also adjusted the minimum $g_{\mathrm{s}}$ threshold by $\beta_{\text {soil }}$ at every time step. Each simulation was run for 25 years with monthly output to determine the long-term impact of changing minimum conductance, and for 1 year with half-hourly output to determine the changes in diel patterns.

\subsection{Data collection}

Values of $g_{\mathrm{s}, \mathrm{n}}$ were obtained from field and glasshouse studies, using Scopus (www.scopus.com), with data for 204 records across 150 species and cultivars (Table S1). Records available were predominately for temperate plants (93 records) and crops (34), with more data available for broad-leaf plant types (89) than needle-leaf plants (16; Zeppel et al., 2014). The data were collated by plant functional type (PFT), with means, medians, and standard deviations for each PFT presented in Table 1. Simulations presented here were run with mean values for each PFT, though median val- ues were also tested and are presented in Figs. S3 and S4 in the Supplement. Since there is large variability in the PFT responses, we present the range of variability in Fig. S2.

The measurements of each $g_{\mathrm{s}, \mathrm{n}}$ value are generally obtained from steady-state porometers, diffusion porometers, Licor 1600 and Licor 6400 gas exchange systems (Caird et al., 2007; Phillips et al., 2010), with a small number converted from sap flux (Benyon, 1999) using an inverted Penman-Monteith equation. Different sampling methods may lead to different estimates of $g_{\mathrm{s}, \mathrm{n}}$, and measurable $g_{\mathrm{s}, \mathrm{n}}$ typically only occurs where VPD is above zero. For example, using a cuvette clamped over the leaf, which changes the leaf boundary layers, will be different compared to measurements from sap flow with an unaltered boundary layer. Data for $g_{\mathrm{s}, \mathrm{n}}$ were typically reported during well-watered conditions, which is ideal because the CLM4.5 calculates stomatal $g_{\mathrm{s}}$ without water stress and then adjusts $g_{o}$ values (and modifications additionally adjust $g_{\text {night }}$ and $g_{\min }$ thresholds) using a soil wetness scalar.

\subsection{Terrestrial coupling index}

To investigate the impact of stomatal conductance changes on the atmosphere, a terrestrial coupling index was calculated, allowing examination of the influence of a minimum $g_{\mathrm{s}}$ threshold on land-atmosphere coupling. Following Dirmeyer (2011), the terrestrial segment of land-atmosphere coupling is defined as follows:

Terrestrial coupling index $(\mathrm{TCI})=\sigma_{w} \times \beta_{w, \mathrm{ET}}$,

where $\sigma_{w}$ is the standard deviation of root-zone soil moisture relevant for transpiration across a given season (e.g., 25 years times 3 summer months), and $\beta_{w \text {,ET }}$ is the linear slope of monthly mean evapotranspiration and root-zone soil moisture. The TCI captures the variability $\left(\sigma_{w}\right)$ and sensitivity of evapotranspiration to changes in soil moisture and returns units equivalent to those of evapotranspiration. Therefore, for a region to have high TCI, soil moisture must have high variability, thus enabling any evapotranspiration-soil moisture sensitivity to manifest in the climate system. While this is strictly a metric for defining the terrestrial component of coupling, the terrestrial component has been used as a surrogate for the total soil moisture-precipitation coupling pattern because of the strong spatial pattern correlation (Wei and Dirmeyer, 2012).

\section{Results and discussion}

\subsection{Implementation of $g_{\mathrm{s}, \mathrm{n}}$}

Incorporating observed minimum constraints on $g_{\mathrm{s}}$ in all modified simulations increased $g_{\mathrm{s}}$ and transpiration compared to the control simulation, illustrated in Fig. 1 for a highly impacted semi-arid location in Ethiopia (see Fig. S1 


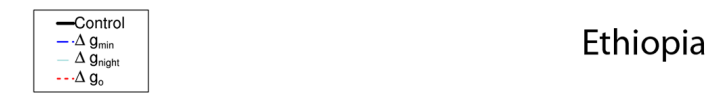

(a)

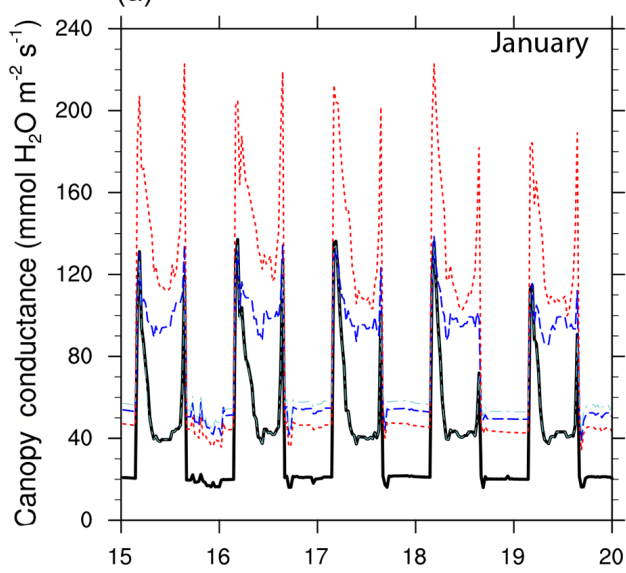

(c)

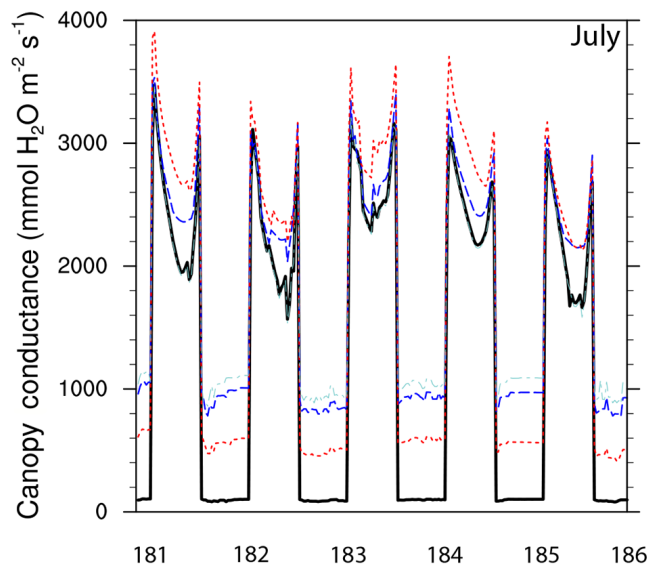

(b)

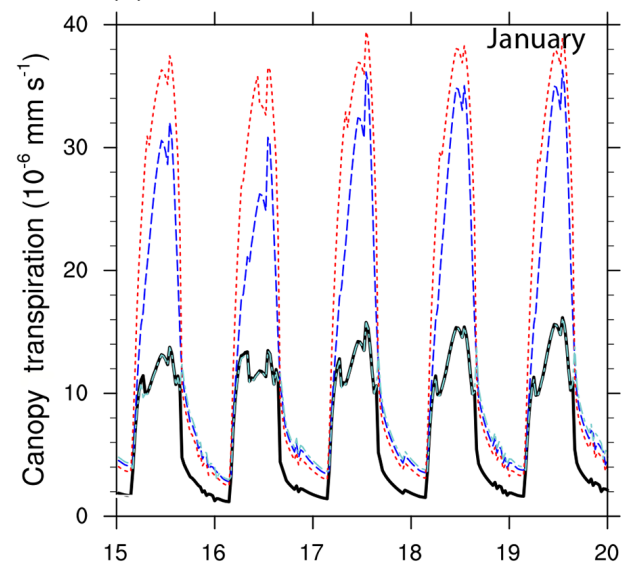

(d)

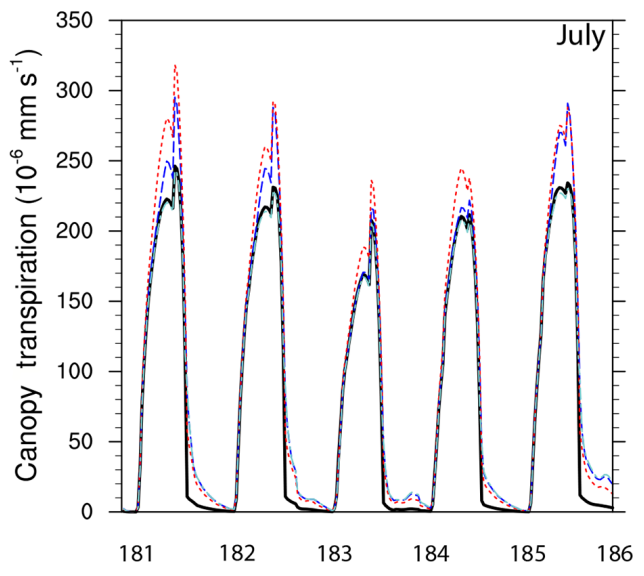

Day of year

Figure 1. Diurnal time series of canopy conductance (a, c) and transpiration (b, d) for Ethiopia over 5 days in mid-January (a-b) and midJuly (c-d). The control simulation (solid black line) had lower conductance and transpiration than the $\Delta g_{o}$ simulation (dotted red line) and the $\Delta g_{\min }$ simulation (dashed blue line). The $\Delta g_{\text {night }}$ simulation (dot-dashed teal line) had higher nighttime conductance and transpiration than the control simulation, but similar daytime conductance and transpiration, allowing for daytime conductance to fall below the nighttime threshold. The $\Delta g_{o}$ simulation added the observed $g_{\mathrm{s}, \mathrm{n}}$ values to the conductance calculation at every time, day or night, which is not theoretically aligned with the function of including observed $g_{\mathrm{s}, \mathrm{n}}$. As a result, the $\Delta g_{o}$ simulation was eliminated from further analyses. Note that all minimum thresholds $\left(g_{o}, g_{\text {night }}\right.$, and $\left.g_{\min }\right)$ were adjusted using a soil moisture scalar.

for other regions). The large variability in the observational dataset causes substantial uncertainty in the simulations, masking the differences among parameterizations and highlighting the impact of $g_{\mathrm{s}, \mathrm{n}}$ on transpiration (Fig. S2). The sensitivity of $g_{\mathrm{s}}$ and transpiration to the altered $g_{o}$ parameter in the $\Delta g_{o}$ simulation is large (Barnard and Bauerle, 2013; Bowden and Bauerle, 2008). Since the higher $g_{o}$ is added to $g_{\mathrm{s}}$ in the BWB calculation at every model time step (see Eq. 1), altering $g_{o}$ increases transpiration throughout the entire diel cycle, and produces changes in the daytime evaporative flux that are not supported by observations of $g_{\mathrm{s}, \mathrm{n}}$. We consider that uniformly adjusting the $g_{o}$ parameter does not represent the correct implementation of observed $g_{\mathrm{s}, \mathrm{n}}$ values.

If $g_{o}$ cannot be equated to plant minimum $g_{\mathrm{s}}$ in the BWB paradigm, this raises the possibility of whether $g_{o}$ has a theoretical interpretation beyond an empirical fitting parameter. It is possible that $g_{o}$ is equivalent to cuticular conductance $\left(g_{\text {cut }}\right)$, or conductance that is not regulated by the stomatal guard cells (Caird et al., 2007), occurring during the day and night. Niyogi and Raman (1997) describe $g_{o}$ as cuticular conductance, though there is no record of $g_{o}$ being tested or described as $g_{\text {cut }}$ previously. Studies that 

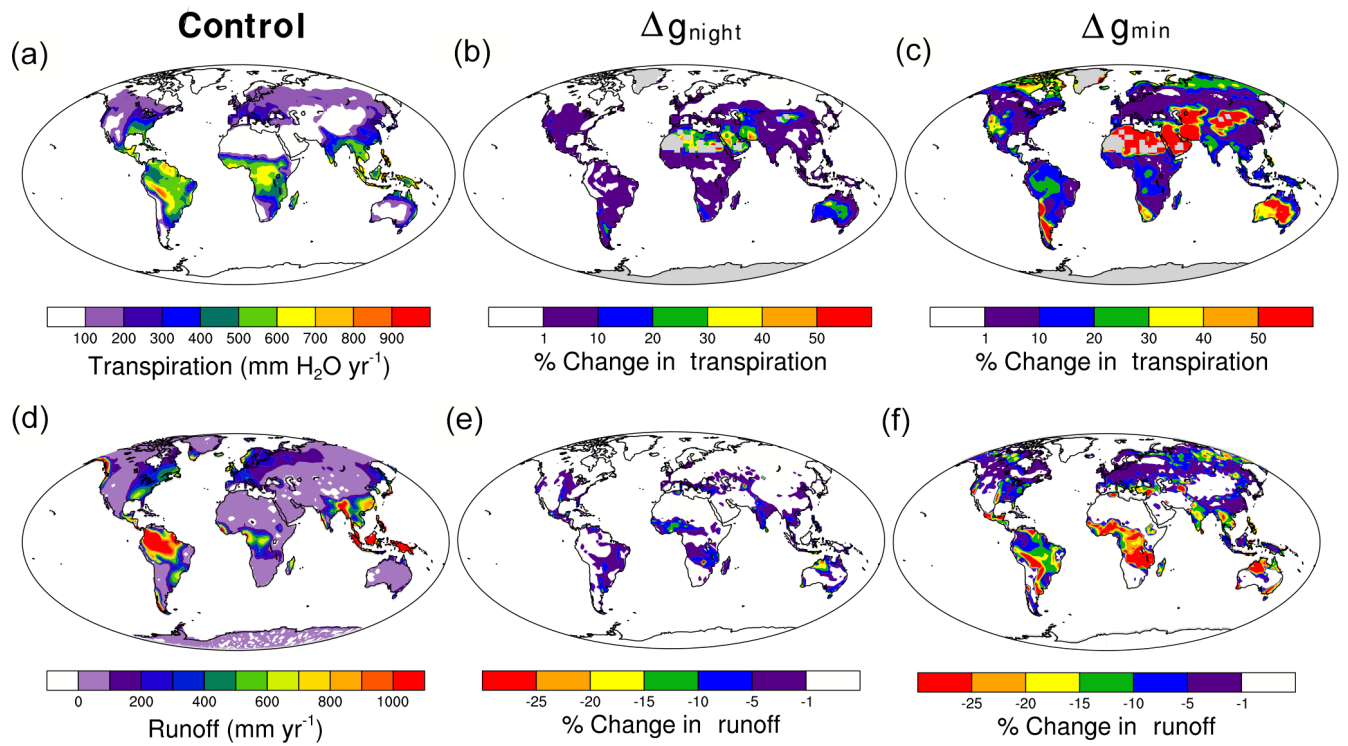

(e)

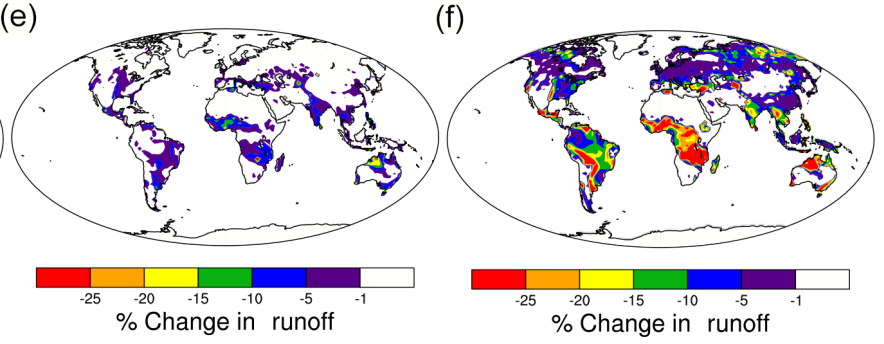

(g)

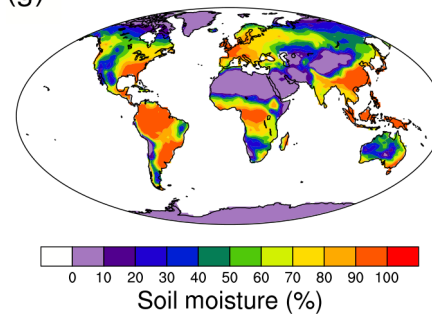

(h)

(i)

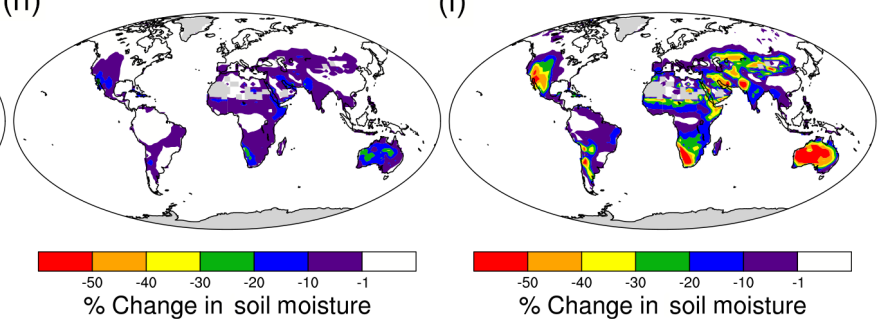

Figure 2. Simulated average transpiration (a), runoff (d), and soil moisture (g) for a control simulation, and percent change from control in transpiration (b-c), runoff (e-f), and soil moisture $(\mathbf{h}-\mathbf{i})$ after including a nighttime threshold $\left(\Delta g_{\text {night }} ; \mathbf{b}, \mathbf{e}, \mathbf{h}\right)$ or a minimum $g_{\mathrm{s}}$ threshold $\left(\Delta g_{\min } ; \mathbf{c}, \mathbf{f}, \mathbf{i}\right)$ based on observational data. Note that both nighttime and minimum thresholds were adjusted based on a soil moisture scalar.

have quantified $g_{\text {cut }}$ found that $g_{\text {cut }}$ was a low proportion, $<10 \%$, of total $g_{\mathrm{s}}$ and less than measured $g_{\mathrm{s}, \mathrm{n}}$ (Caird et al., 2007; Zeppel et al., 2014). The values of $g_{o}$ used in current implementations of the Ball-Berry model for $\mathrm{C}_{3}$ plants $\left(10 \mathrm{mmol} \mathrm{m}^{-2} \mathrm{~s}^{-1}\right)$ fall within the range of measured $g_{\text {cut }}$ values ( 4 to $20 \mathrm{mmol} \mathrm{m}^{-2} \mathrm{~s}^{-1}$; Caird et al., 2007). Assuming $g_{o}$ does have a theoretical function of representing $g_{\text {cut }}$, rather than $g_{\mathrm{s}, \mathrm{n}}$, incorporating an observed threshold of minimum $g_{\mathrm{s}}$ is necessary. Whether $g_{o}$ functions theoretically as $g_{\text {cut }}$ in the BWB model needs further evaluation, as adjusting simulated $g_{o}$ has large impacts on canopy conductance and transpiration (Fig. 1; Barnard and Bauerle, 2013). Regardless, observed $g_{\mathrm{s}, \mathrm{n}}$ is larger than modeled $g_{o}$ and functions differently, and therefore should be considered independently in model parameterizations.

The $\Delta g_{\text {min }}$ and $\Delta g_{\text {night }}$ simulations represent the intended change in minimum $g_{\mathrm{s}}$ with greater fidelity, by limiting the minimum value without increasing $g_{\mathrm{s}}$ at every model time step. Interestingly, in restricting only nighttime conductance, the $\Delta g_{\text {night }}$ simulation allows daytime $g_{\text {s }}$ to decrease below the nighttime threshold during the dry season in semi-arid ecosystems (Fig. 1a). This occurs when $A_{\mathrm{n}}$ nears zero in shade or low humidity, causing $g_{\mathrm{s}}$ to fall to the default (lower) $g_{o}$. In contrast, the $\Delta g_{\min }$ simulation restricts minimum $g_{\mathrm{s}}$ at all times, and therefore daytime values are never less than the water-adjusted $g_{\mathrm{s}, \mathrm{n}}$. This increases canopy-averaged daytime $g_{\mathrm{s}}$, and hence transpiration, compared to the unmodified simulation whenever daytime $g_{\mathrm{s}}$ values fall below the minimum threshold (Fig. 1a, c).

The data in Table $\mathrm{S} 1$ are a compilation of all available published $g_{\mathrm{s}, \mathrm{n}}$ data to date, and report $g_{\mathrm{s}, \mathrm{n}}$ values for 204 distinct plants. Of these, only four plants exhibit higher $g_{\mathrm{s}, \mathrm{n}}$ than daytime $g_{\mathrm{s}}$, and two of those are Crassulacean acid metabolism (CAM) plants, which by definition open their stomata at night to gain carbon dioxide and close their stomata during the day, and were not used in our parameterization. These data suggest that, as expected, $g_{\mathrm{s}, \mathrm{n}}$ is typically less than daytime $g_{\mathrm{s}}$. Most data presented in Table S1 are average values under non-drought stressed conditions, and are likely only reported for leaves in sunlit canopy layers. Thus, these data do not elucidate whether, at any given time, daytime values might drop below the nighttime threshold, but only suggest that, on average, they do not. 


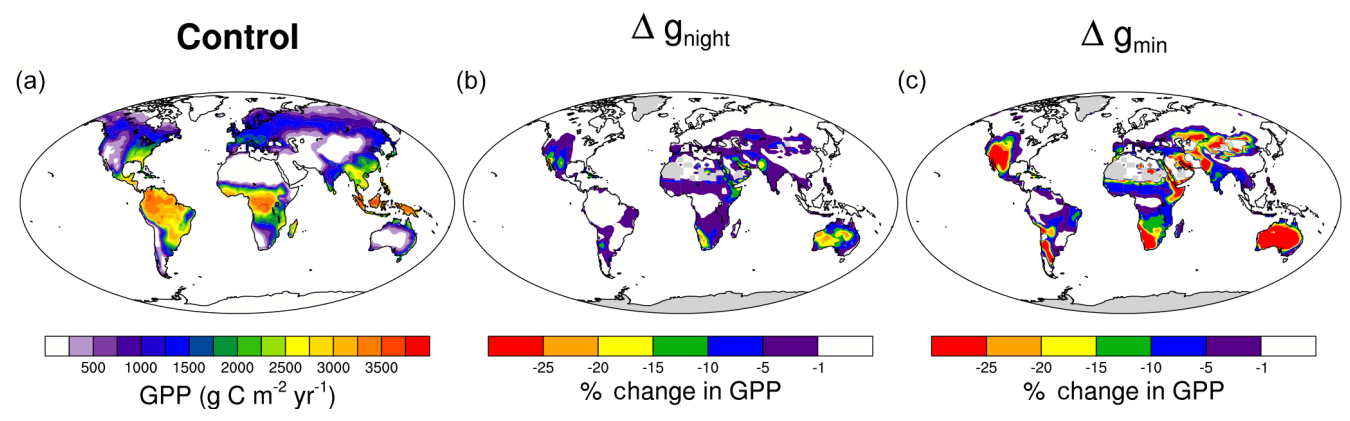

Figure 3. Average gross primary productivity (GPP) for a control simulation (a), and percent change from control (b-c) after including a nighttime threshold $\left(\Delta g_{\text {night }} ; \mathbf{b}\right)$ or a minimum $g_{\mathrm{s}}$ threshold $\left(\Delta g_{\min } ; \mathbf{c}\right)$ based on observational data. Note that both nighttime and minimum thresholds were adjusted based on a soil moisture scalar.

In the context of the model simulations, low daytime $g_{\mathrm{s}}$ occurs any time that $A h_{\mathrm{r}} / \mathrm{C}$ is low. These are conditions which are poorly illuminated (in shade or at dawn/dusk and night), or when humidity is low. The CLM4.5SP contains a representation of the shaded canopy, which has lower $g_{\mathrm{s}}$ and often reaches the minimum daytime threshold $\left(g_{o}\right.$ in the unmodified, $\Delta g_{o}$, and $\Delta g_{\text {night }}$ simulations, and $g_{\mathrm{s}, \mathrm{n}}$ in the $\Delta g_{\min }$ simulation). The central issue in determining whether the $\Delta g_{\min }$ or $\Delta g_{\text {night }}$ simulation is a better representation of minimum $g_{\mathrm{s}}$ is whether, under the same conditions in the real world, daytime $g_{\mathrm{s}}$ might be lower than $g_{\mathrm{s}, \mathrm{n}}$. For example, if observational data support that daytime $g_{\mathrm{s}}$ is less than $g_{\mathrm{s}, \mathrm{n}}$ in shaded canopy layers given the same water availability, then the $\Delta g_{\text {night }}$ simulation is a better parameterization. However, if observational data suggest that daytime $g_{\mathrm{s}}$ is consistently higher than $g_{\mathrm{s}, \mathrm{n}}$, then the $\Delta g_{\min }$ simulation is a better parameterization. While observational data are not available to specifically answer this question, the available data presented in Table S1 and data from Dawson et al. (2007), which suggest that $g_{\mathrm{s}, \mathrm{n}}$ is a fraction of daytime $g_{\mathrm{s}}$, imply that daytime $g_{\mathrm{s}}$ is on average higher than $g_{\mathrm{s}, \mathrm{n}}$, providing partial support for the $\Delta g_{\min }$ implementation. A different implementation of $g_{\mathrm{s}, \mathrm{n}}$ might calculate $g_{\mathrm{s}, \mathrm{n}}$ as a proportion of daytime $g_{\mathrm{s}}$, based on Dawson et al. (2007), who find that $g_{\mathrm{s}, \mathrm{n}}$ is a proportion of daytime $g_{\mathrm{s}}$ that changes based on days since last rainfall. We do not test this potential method here, but acknowledge it as a viable alternative to be considered.

The possible existence of a higher $g_{\mathrm{s}, \mathrm{n}}$ compared to daytime $g_{\mathrm{s}}$ raises an interesting question about the potential selective advantage for leaves with a high $g_{\mathrm{s}, \mathrm{n}}$. It is hypothesized that high $g_{\mathrm{s}, \mathrm{n}}$ may provide a beneficial function to the plant, such as embolism repair or phloem transport (e.g., Dawson et al., 2007). Additionally, $g_{\mathrm{s}, \mathrm{n}}$ may contribute to xylem refilling, potentially improving carbon gain by making water available when light conditions allow for photosynthesis (Dawson et al. 2007). Critically, it is not clear whether these potential functions are only relevant at night (and daytime $g_{\mathrm{s}}$ can be lower than $g_{\mathrm{s}, \mathrm{n}}$ ), or whether high $g_{\mathrm{s}, \mathrm{n}}$ is representative of a general strategy of higher overall minimum $g_{\mathrm{s}}$.
We are not aware of data that exist to support either possibility, and advocate for observations that will help determine the functional significance of $g_{\mathrm{s}, \mathrm{n}}$.

From a model or theoretical perspective, it is important to note that the reason that simulated $g_{\mathrm{s}}$ values are reduced to as low as $10 \mathrm{mmol} \mathrm{m}^{-2} \mathrm{~s}^{-1}$ (or lower, if down-regulated for water stress) is a function of the universal parameterization of all $\mathrm{C}_{3}$ plants with that value of $g_{o}$. Given that it is unlikely that this value is universal for all plants, we consider that the large difference between the $\Delta g_{\text {min }}$ or $\Delta g_{\text {night }}$ simulations is an artifact of the poorly constrained parameterization of the daytime BWB model.

It should be noted that all the minimum thresholds implemented in our simulations $\left(\Delta g_{o}, \Delta g_{\text {night }}\right.$, and $\left.\Delta g_{\text {min }}\right)$ are adjusted by a soil water scalar $\left(\beta_{\text {soil }}\right)$. Therefore, the nighttime $\left(\Delta g_{\text {night }}\right)$ and the minimum $\left(\Delta g_{\text {min }}\right)$ thresholds are altered according to the degree of soil moisture stress. When the daytime $g_{\mathrm{s}}$ value is lower than the $g_{\text {night }}$ threshold in the $\Delta g_{\text {night }}$ simulation (Fig. 1c), the $g_{\text {night }}$ threshold is already down-regulated for water stress. In this scenario, the daytime minimum $g_{\mathrm{s}}$ is less than the nighttime $g_{\mathrm{s}}$ when water stress is equivalent.

Responses to dry soil conditions are mediated both through the minimum $g_{\mathrm{s}}$ values, and through the impact of soil moisture on photosynthetic capacity and leaf maintenance respiration, which are also multiplied by $\beta_{\text {soil }}$. Many of the impacts of our simulations result from feedbacks between higher transpiration rates resulting in faster depletion of soil moisture store, and therefore greater constraint on photosynthesis. These results are all emergent features of the model and should not be interpreted as direct results of the altered parameterization.

\subsection{Global water and carbon}

When averaged over 25 years, incorporating observed rates of $g_{\mathrm{s}, \mathrm{n}}$ in the $\Delta g_{\min }$ simulation increased transpiration losses by up to $30 \%$ in the Amazon, and $>30 \%$ in some arid regions, in part due to the small absolute magnitude of available soil water (Fig. 2a-c). Semi-arid regions are primarily 


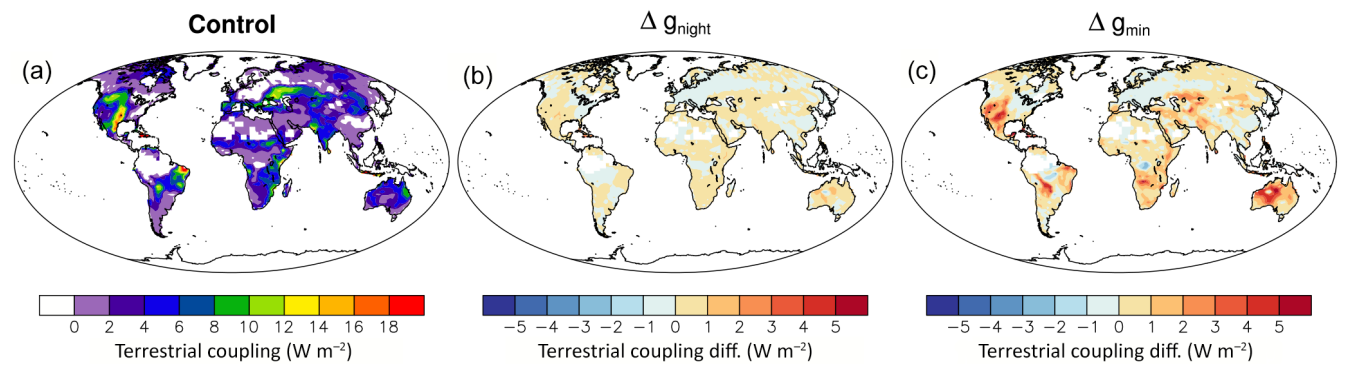

Figure 4. Terrestrial coupling for June-July-August for a control simulation (a), and the difference from control (b-c) after including a nighttime threshold $\left(\Delta g_{\text {night }} ; \mathbf{b}\right)$ or a minimum $g_{\mathrm{s}}$ threshold value $\left(\Delta g_{\min } ; \mathbf{c}\right)$ based on observational data. Note that both nighttime and minimum thresholds were adjusted based on a soil moisture scalar.

Table 2. Global values from CLM simulations and observations*.

\begin{tabular}{llrrr}
\hline Simulation & $\begin{array}{l}g_{\mathrm{s}, \mathrm{n}} \\
\text { data used }\end{array}$ & $\begin{array}{r}\mathrm{GPP} \\
\left(\mathrm{Pg} \mathrm{C} \mathrm{yr}^{-1}\right)\end{array}$ & $\begin{array}{r}\mathrm{ET} \\
\left(10^{3} \mathrm{~km}^{3} \mathrm{yr}^{-1}\right)\end{array}$ & $\begin{array}{r}\text { Runoff } \\
\left(10^{3} \mathrm{~km}^{3} \mathrm{yr}^{-1}\right)\end{array}$ \\
\hline Control & n/a & 157.83 & 65.6148 & 30.462 \\
$g_{o}$ & Mean & 152.56 & 72.6555 & 24.2141 \\
$g_{\text {night }}$ & Mean & 156.068 & 66.0926 & 30.0724 \\
$g_{\text {min }}$ & Mean & 151.252 & 68.6843 & 27.8161 \\
$g_{o}$ & Median & 153.641 & 71.5441 & 25.1739 \\
$g_{\text {night }}$ & Median & 156.346 & 66.031 & 30.119 \\
$g_{\text {min }}$ & Median & 152.385 & 67.8881 & 28.51 \\
Observation & & $119-175$ & 65.13 & 37.7521 \\
\hline
\end{tabular}

* Global gross primary productivity (GPP), evapotranspiration (ET), and runoff values. Observed values presented in Bonan et al. (2011), Welp et al. (2011), and Lawrence et al. (2011). n/a - not applicable

broad-leaf shrub and $\mathrm{C}_{3}$ grass PFTs that have particularly high values (130 and $156 \mathrm{mmol} \mathrm{m}^{-2} \mathrm{~s}^{-1}$ respectively) of observed $g_{\mathrm{s}, \mathrm{n}}$ (Table 1), and have high nighttime vapor pressure deficits that interact with higher minimum $g_{\mathrm{s}}$ values, causing large nighttime transpiration rates. Using median rather than mean values caused only small $(<1.5 \%)$ differences in global transpiration (Figs. S3, S4). Though the magnitude of response is different depending on parameterization used, the increases in transpiration imply that current model estimates of plant water loss are underestimated in many regions.

Simulated higher transpiration resulting from higher minimum $g_{\mathrm{s}}$ also has ecosystem-scale ramifications for hydrology (McLaughlin et al., 2007). For example, the increased transpiration resulted in drier soils compared to the control simulation (Fig. $2 \mathrm{~g}-\mathrm{i}$ ), with $\Delta g_{\min }$ causing $>40 \%$ soil moisture decreases in semi-arid ecosystems like the southwestern United States and much of Australia ( $>10 \%$ in $\Delta g_{\text {night }}$ ). Additionally, the $\Delta g_{\text {min-estimated changes to surface runoff are }}$ large in some regions, such as the $10-25 \%$ decreases in the tropics (5-10\% in $\Delta g_{\text {night }}$; Fig. $\left.2 d-f\right)$, suggesting that current runoff estimates may be too large. It should be noted that the difference between the $\Delta g_{\min }$ and $\Delta g_{\text {night }}$ simulations is largely due to changes in minimum $g_{\mathrm{s}}$ that affect daytime $g_{\mathrm{s}}$ (see Sect. 3.1). Hydrologic changes in soil moisture and runoff in response to increased $g_{\mathrm{s}}$ have previously been documented in catchments in the southeastern United States (McLaughlin et al., 2007), and our results suggest that changes to stomatal conductance have similar consequences in CLM4.5SP simulations. Additionally, increasing minimum $g_{\mathrm{s}}$ caused gross primary productivity (GPP) to decrease (Fig. 3) by 10 to $>25 \%$ in many semi-arid regions. These are regions where water availability already restricts GPP, and the decreases in soil moisture caused by higher transpiration likely impart even more drought-induced stomatal closure.

To more directly evaluate the potential influence of minimum $g_{\mathrm{s}}$ on the climate system, we calculate the change in terrestrial coupling to the atmosphere. The terrestrial coupling index (Dirmeyer, 2011) estimates the degree to which changes in soil moisture control surface energy fluxes to the atmosphere. This study uses root-zone soil moisture, rather than soil moisture over spatially constant soil depth, to highlight the direct impact of vegetation and minimum $g_{\mathrm{s}}$ on surface fluxes. Here we calculate the terrestrial coupling index during boreal summer months when warmer temperatures allow for the highest $g_{\mathrm{s}}$ rates. We find that the terrestrial coupling strength increases when using the $\Delta g_{\min }$ implementation, but is generally unchanged for $\Delta g_{\text {night }}$ (Fig. 4), meaning root-zone soil moisture exerts a greater control on surface flux variability for $\Delta g_{\min }$, largely due to the impact this sim- 


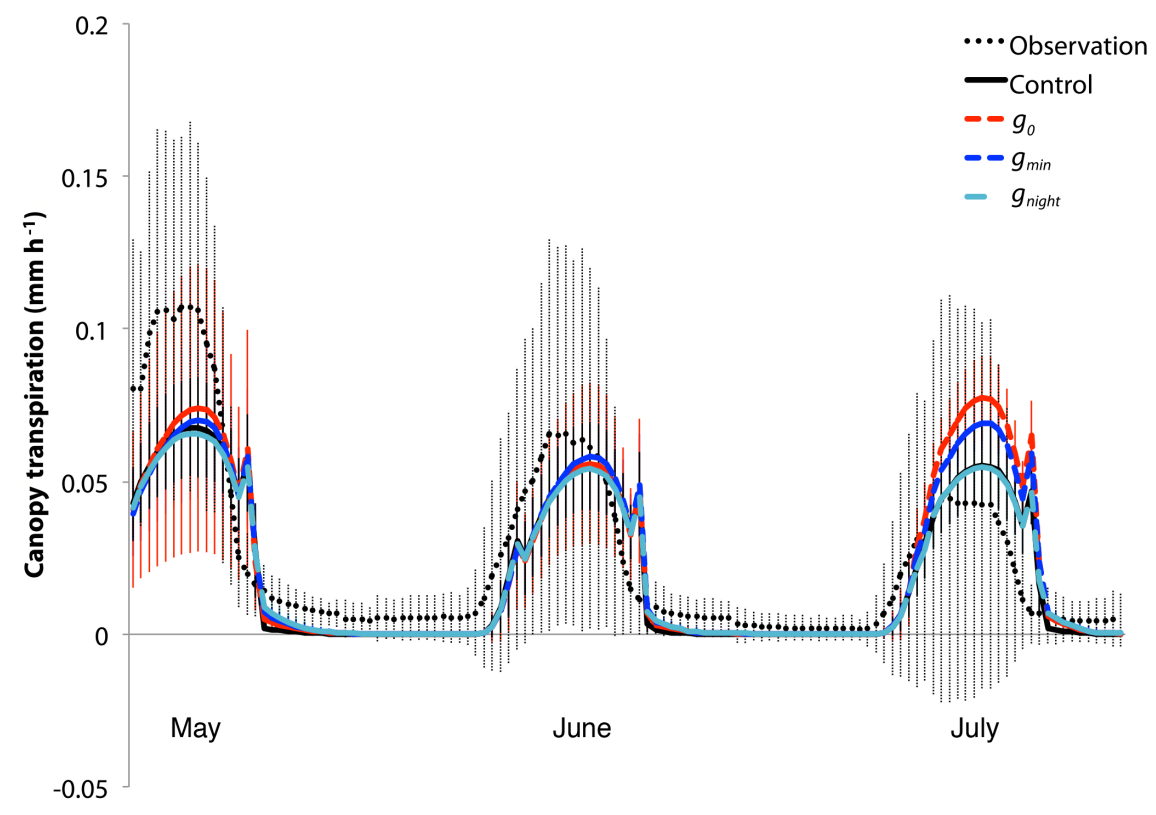

Figure 5. Average diel canopy transpiration for the months of May, June, and July in Castlereagh, Australia (observation, dotted black line), estimated from sap flux measurements of Red Gum and Iron Bark, the dominant tree species in the canopy. Average simulated canopy transpiration for the grid cell corresponding to Castlereagh, Australia, for the control (unmodified; solid black line), $\Delta g_{o}$ (Ball-Berry $g_{o}$ parameter adjusted; red line), $\Delta g_{\text {night }}$ (minimum nighttime threshold added; teal line), and $\Delta g_{\text {min }}$ (minimum conductance threshold added; blue line) simulations. Error bars corresponding to the observations (dashed) and each simulation (solid) are colored accordingly, and are calculated as \pm one standard deviation from the mean. Note that the simulations use meteorological forcings from an atmospheric dataset (see Methods), not the local meteorology from when the measurements were collected (some meteorological data were collected at the site, but not all variables required by the model). The simulated grid cell covers a much larger area than the observational data collection site.

ulation has on daytime $g_{\mathrm{s}}$. This increased terrestrial coupling to the atmosphere largely mirrors the reductions in GPP and soil moisture in semi-arid ecosystems, and may reinforce climate extremes such as droughts or heat waves (Hirschi et al., 2011; Miralles et al., 2014).

\subsection{Evaluating $g_{\mathrm{s}, \mathrm{n}}$}

Evaluating the performance of the new $g_{\mathrm{s}, \mathrm{n}}$ parameterizations is challenging for numerous reasons. First, our model scales from leaf-level $g_{\mathrm{s}}$ and $g_{\mathrm{s}, \mathrm{n}}$ estimates to canopy transpiration. The best way of evaluating the model is to compare simulated and observed canopy transpiration because the model captures the average of an entire canopy, which is comprised of multiple plant functional types, rather than individual plant functional types. Incorporating realistic minimum $g_{\mathrm{s}}$ increases global evapotranspiration and decreases global runoff compared to globally scaled observations, while estimates of GPP from all simulations fall within the range of global GPP estimates from observations (Table 2; Bonan et al., 2011, 2012; Li et al., 2011). However, these comparisons should be used with caution, since eddy covariance data used in estimating the GPP and evapotranspiration observations are susceptible to errors at night (Fisher et al., 2007; van Gorsel et al., 2008; Kirschbaum et al., 2007; Medlyn et al., 2005) due to a lack of sufficient canopy turbulence that precludes detection of nighttime transpiration using this measurement methodology, and are not useful for evaluating the changes in water fluxes tested in this study. Other data for evaluating model responses to minimum $g_{\mathrm{s}}$ on large spatial scales are not yet available.

A comparison of simulated canopy transpiration to transpiration calculated from sap-flux data in Australia (Fig. 5) illustrates that a minimum $g_{\mathrm{s}}$ threshold changes transpiration estimates during the early part of the night, though simulated nighttime rates are still low compared to observations. All model parameterizations fall within the observational range of uncertainty, but under-predict nighttime and midday canopy transpiration during May and June, and over-predict midday canopy transpiration in July. The lack of fidelity between the various model parameterizations and the observations is likely affected by the fact that observed meteorological data were unavailable to force the model. Therefore, key parameters driving both daytime and nighttime transpiration fluxes, such as VPD and soil water availability, were likely different in the model simulations compared to the actual meteorological conditions at Castlereagh, Australia, during data collection. Additionally, because sap flow is measured at the base of the tree, there is typically a lag between when sap flow is measured and when the canopy transpires, and this lag is also notable in comparing observed sap flow with sim- 
ulated estimates of transpiration. Estimating nighttime transpiration using sap-flow methodology is also convoluted with the refilling of aboveground water stores depleted during the day, and thus is not directly comparable to our simulations. It should also be noted that the model does not have a semiarid plant functional type, so semi-arid plants are typically represented in the model as deciduous plant functional types.

Given that our study focused only on one aspect of the $g_{\mathrm{s}}$ formulation within a land-surface model, evaluating daytime $g_{\mathrm{s}}$ and other aspects of the BWB model function (i.e., photosynthetic drivers of daytime $g_{\mathrm{s}}$, feedbacks to water availability, etc.) are all subject to pre-existing deficiencies in the representation of a host of other model processes. For example, there are only two values of the $g_{1}$ (slope) parameter in the BWB model, one for $\mathrm{C}_{3}$ and one for $\mathrm{C}_{4}$ plants (Sellers et al., 1996), and this parameter has not been modified or comprehensively evaluated within the context of the CLM4.5SP. Indeed, the use of the BWB model at all is currently the subject of some debate (Bonan et al., 2014; De Kauwe et al., 2015), and this study additionally highlights how the empirical nature of the BWB model leads to difficulties when attempting to implement mechanistic processes. Further, daytime $g_{\mathrm{s}}$ is also dependent on the photosynthetic capacity, and observations of $V_{\text {cmax }}$ and $J_{\max }$ (Bonan et al., 2011; Kattge and Knorr, 2007) indicate very wide ranges of plant functional type variation in these properties, also limiting our confidence that the globally averaged parameters used in the default model will lead to accurate $g_{\mathrm{s}}$ and transpiration at most locations. We choose not to focus on these and other parameters that effect daytime $g_{\mathrm{s}}$, as it does not directly impact the representation of $g_{\mathrm{s}, \mathrm{n}}$, and is therefore beyond the scope of this paper.

\section{Conclusions}

The rate of minimum $g_{\mathrm{s}}$ estimated from the BWB model used in many global land-surface models is typically smaller than observed $g_{\mathrm{s}, \mathrm{n}}$ (Barnard and Bauerle, 2013), as demonstrated in a review of 204 species (Zeppel et al., 2014). Including a nighttime or minimum $g_{\mathrm{s}}$ threshold based on observations results in simulated hydrologic changes, such as decreased soil moisture and runoff (Fig. 2), particularly in semi-arid regions where water availability already restricts growth. In addition to potentially increasing drought stress in sensitive regions, this has the impact of reducing plant growth (Fig. 3) and changing the modeled terrestrial coupling to the atmosphere (Fig. 4). The difference between the $\Delta g_{\min }$ and $\Delta g_{\text {night }}$ simulations highlights one outstanding uncertainty: does minimum daytime $g_{\mathrm{s}}$ decrease below nighttime $g_{\mathrm{s}}$ ? While the balance of our arguments favors the $\Delta g_{\min }$ implementation of $g_{\mathrm{s}, \mathrm{n}}$, this study primarily illustrates the potential sensitivity of global simulations to minimum $g_{\mathrm{s}}$ considerations, and serves as motivation for additional field experiments, particularly in semi-arid areas, to discern bet- ter representations of low $g_{\mathrm{s}}$ conditions during daytime and nighttime. To better understand the future of these sensitive ecosystems, widespread field observations, quantification of minimum daytime $g_{\mathrm{s}}$, and a better understanding of the physiological causes and consequences of nighttime transpiration are necessary so that land-surface models can robustly incorporate observations and theory.

\section{Code and data availability}

The code for CLM4.5 is publicly available through a Subversion code repository: https://svn-ccsm-models. cgd.ucar.edu/cesm1/release_tags/cesm1_2_2. To access the code, fill out a short, required registration to get a user name and password, necessary to gain access to the repository: http://www.cesm.ucar.edu/models/register/ register_cesm.cgi, http://www.cesm.ucar.edu/models/cesm1. 2/clm/CLM45_Tech_Note.pdf. The CLM4.5 User's Guide can be found at http://www.cesm.ucar.edu/models/cesm1.2/ $\mathrm{clm} / \mathrm{models} / \mathrm{lnd} / \mathrm{clm} / \mathrm{doc} /$ UsersGuide/book1.html. All stomatal conductance data used in developing the implementations can be found in Table S1. The modified code for CLM4.5 used in the $\delta g_{o}, \delta g_{\text {night }}$, and $\delta g_{\text {min }}$ simulations, as well as the data from the model simulations used in these analyses, are available upon request.

\section{The Supplement related to this article is available online at doi:10.5194/gmd-10-321-2017-supplement.}

Author contributions. D. L. Lombardozzi, M. J. B. Zeppel, and R. A. Fisher conceived the project. M. J. B. Zeppel assembled the $g_{\mathrm{s}, \mathrm{n}}$ datasets, D. L. Lombardozzi ran model simulations, and D. L. Lombardozzi and A. Tawfik analyzed model simulations, with guidance from R. A. Fisher. All authors contributed to writing the paper.

Acknowledgement. We thank Gordon Bonan for useful discussion on the manuscript, and the reviewers for the constructive comments that have improved the final version of this paper. D. L. Lombardozzi was supported through the DEB Ecosystem Science Cluster and National Science Foundations grant EF-1048481. M. J. B. Zeppel was supported by ARC DECRA DE120100518. R. A. Fisher was supported by the National Science Foundation and the National Center for Atmospheric Research, and A. Tawfik was supported by the National Science Foundation grant 0947837 for Earth System Modeling post-doctoral fellows. The National Center for Atmospheric Research is funded by the National Science Foundation.

Edited by: T. Kato

Reviewed by: J. B. Fisher, K. Tu, and one anonymous referee 


\section{References}

Ball, J. T.: An Analysis of Stomatal Conductance, Stanford University, 1988.

Ball, J. T., Woodrow, I. E., and Berry, J. A.: A Model Predicting Stomatal Conductance and its Contribution to the Control of Photosynthesis under Different Environmental Conditions, in: Progress in Photosynthesis Research, edited by: Biggins, J., 221224, Springer Netherlands, doi:10.1007/978-94-017-0519-6_48, 1987.

Barnard, D. M. and Bauerle, W. L.: The implications of minimum stomatal conductance on modeling water flux in forest canopies, J. Geophys. Res.-Biogeo., 118, 1322-1333, doi:10.1002/jgrg.20112, 2013.

Benyon, R. G.: Nighttime water use in an irrigated Eucalyptus grandis plantation, Tree Phys., 19, 853-859, doi:10.1093/treephys/19.13.853, 1999.

Bonan, G. B., Lawrence, P. J., Oleson, K. W., Levis, S., Jung, M., Reichstein, M., Lawrence, D. M., and Swenson, S. C.: Improving canopy processes in the Community Land Model version 4 (CLM4) using global flux fields empirically inferred from FLUXNET data, J. Geophys. Res.-Biogeo., 116, G02014, doi:10.1029/2010JG001593, 2011.

Bonan, G. B., Oleson, K. W., Fisher, R. A., Lasslop, G., and Reichstein, M.: Reconciling leaf physiological traits and canopy flux data: Use of the TRY and FLUXNET databases in the Community Land Model version 4, J. Geophys. Res.-Biogeo., 117, G02026, doi:10.1029/2011JG001913, 2012.

Bonan, G. B., Williams, M., Fisher, R. A., and Oleson, K. W.: Modeling stomatal conductance in the earth system: linking leaf water-use efficiency and water transport along the soil-plantatmosphere continuum, Geosci. Model Dev., 7, 2193-2222, doi:10.5194/gmd-7-2193-2014, 2014.

Bowden, J. D. and Bauerle, W. L.: Measuring and modeling the variation in species-specific transpiration in temperate deciduous hardwoods, Tree Physiol., 28, 1675-1683, 2008.

Caird, M. A., Richards, J. H., and Donovan, L. A.: Nighttime stomatal conductance and transpiration in C-3 and C-4 plants, Plant Physiol., 143, 4-10, doi:10.1104/pp.106.092940, 2007.

Collatz, G. J., Ball, J. T., Grivet, C., and Berry, J. A.: Physiological and environmental regulation of stomatal conductance, photosynthesis and transpiration: a model that includes a laminar boundary layer, Agr. Forest Meteorol., 54, 107-136, doi:10.1016/0168-1923(91)90002-8, 1991.

Dawson, T. E., Burgess, S. S. O., Tu, K. P., Oliveira, R. S., Santiago, L. S., Fisher, J. B., Simonin, K. A., and Ambrose, A. R.: Nighttime transpiration in woody plants from contrasting ecosystems, Tree Physiol., 27, 561-575, 2007.

de Dios, V. R., Turnbull, M. H., Barbour, M. M., Ontedhu, J., Ghannoum, O., and Tissue, D. T.: Soil phosphorous and endogenous rhythms exert a larger impact than $\mathrm{CO}_{2}$ or temperature on nocturnal stomatal conductance in Eucalyptus tereticornis, Tree Physiol., 33, 1206-1215, doi:10.1093/treephys/tpt091, 2013.

De Kauwe, M. G., Kala, J., Lin, Y.-S., Pitman, A. J., Medlyn, B. E., Duursma, R. A., Abramowitz, G., Wang, Y.-P., and Miralles, D. G.: A test of an optimal stomatal conductance scheme within the CABLE land surface model, Geosci. Model Dev., 8, 431-452, doi:10.5194/gmd-8-431-2015, 2015.
Dirmeyer, P. A.: The terrestrial segment of soil moistureclimate coupling, Geophys. Res. Lett., 38, L16702, doi:10.1029/2011GL048268, 2011.

Fisher, J. B., Baldocchi, D. D., Misson, L., Dawson, T. E., and Goldstein, A. H.: What the towers don't see at night: nocturnal sap flow in trees and shrubs at two AmeriFlux sites in California, Tree Physiol., 27, 597-610, 2007.

Hetherington, A. M. and Woodward, F. I.: The role of stomata in sensing and driving environmental change, Nature, 424, 901908, doi:10.1038/nature01843, 2003.

Hirschi, M., Seneviratne, S. I., Alexandrov, V., Boberg, F., Boroneant, C., Christensen, O. B., Formayer, H., Orlowsky, B., and Stepanek, P.: Observational evidence for soil-moisture impact on hot extremes in southeastern Europe, Nat. Geosci., 4, 17-21, doi:10.1038/NGEO1032, 2011.

Kattge, J. and Knorr, W.: Temperature acclimation in a biochemical model of photosynthesis: a reanalysis of data from 36 species, Plant Cell Environ., 30, 1176-1190, doi:10.1111/j.13653040.2007.01690.x, 2007.

Kirschbaum, M. U. F., Keith, H., Leuning, R., Cleugh, H. A., Jacobsen, K. L., van Gorsel, E., and Raison, R. J.: Modelling net ecosystem carbon and water exchange of a temperate Eucalyptus delegatensis forest using multiple constraints, Agr. Forest Meteorol., 145, 48-68, doi:10.1016/j.agrformet.2007.04.002, 2007.

Lawrence, D. M., Oleson, K. W., Flanner, M. G., Thornton, P. E., Swenson, S. C., Lawrence, P. J., Zeng, X., Yang, Z.-L., Levis, S., Sakaguchi, K., Bonan, G. B., and Slater, A. G.: Parameterization Improvements and Functional and Structural Advances in Version 4 of the Community Land Model, J. Adv. Model. Earth Syst., 3, M03001, doi:10.1029/2011MS000045, 2011.

Leuning, R.: A critical appraisal of a combined stomatalphotosynthesis model for C3 plants, Plant Cell Environ., 18, 339-355, doi:10.1111/j.1365-3040.1995.tb00370.x, 1995.

Li, H., Huang, M., Wigmosta, M. S., Ke, Y., Coleman, A. M., Leung, L. R., Wang, A., and Ricciuto, D. M.: Evaluating runoff simulations from the Community Land Model 4.0 using observations from flux towers and a mountainous watershed, J. Geophys. Res.-Atmos., 116, D24120, doi:10.1029/2011JD016276, 2011.

McLaughlin, S. B., Wullschleger, S. D., Sun, G., and Nosal, M.: Interactive effects of ozone and climate on water use, soil moisture content and streamflow in a southern Appalachian forest in the USA, New Phytol., 174, 125-136, doi:10.1111/j.14698137.2007.01970.x, 2007.

Medlyn, B. E., Robinson, A. P., Clement, R., and McMurtrie, R. E.: On the validation of models of forest $\mathrm{CO}_{2}$ exchange using eddy covariance data: some perils and pitfalls, Tree Physiol., 25, 839-857, 2005.

Medlyn, B. E., Duursma, R. A., Eamus, D., Ellsworth, D. S., Prentice, I. C., Barton, C. V. M., Crous, K. Y., De Angelis, P., Freeman, M., and Wingate, L.: Reconciling the optimal and empirical approaches to modelling stomatal conductance, Glob. Change Biol., 17, 2134-2144, doi:10.1111/j.1365-2486.2010.02375.x, 2011.

Miralles, D. G., Teuling, A. J., van Heerwaarden, C. C., and VilàGuerau de Arellano, J.: Mega-heatwave temperatures due to combined soil desiccation and atmospheric heat accumulation, Nat. Geosci., 7, 345-349, doi:10.1038/ngeo2141, 2014.

Niyogi, D. S. and Raman, S.: Comparison of Four Different Stomatal Resistance Schemes Using FIFE Observations, J. Appl. 
Meteorol., 36, 903-917, doi:10.1175/1520-0450(1997)036< 0903:COFDSR>2.0.CO;2, 1997.

Oleson, K. W., Lawrence, D. M., Bonan, G. B., Drewniak, B., Huang, M., Koven, C. D., Levis, S., Li, F., Riley, W. J., Subin, Z. M., Swenson, S. C., Thornton, P. E., Bozbiyik, A., Fisher, R. A., Kluzek, E., Lamarque, J.-F., Lawrence, P. J., Leung, L. R., Lipscomb, W., Muszala, S., Ricciuto, D. M., Sacks, W. J., Sun, Y., Tang, J. Y., and Yang, Z.-L.: Technical Description of version 4.5 of the Community Land Model (CLM), NCAR Tech. Note, NCAR/TN-503+STR, doi:10.5065/D6RR1W7M, 2013.

Phillips, N. G., Lewis, J. D., Logan, B. A., and Tissue, D. T.: Interand intra-specific variation in nocturnal water transport in Eucalyptus, Tree Physiol., 30, 586-596, doi:10.1093/treephys/tpq009, 2010.

Scholz, F. G., Bucci, S. J., Goldstein, G., Meinzer, F. C., Franco, A. C., and Miralles-Wilhelm, F.: Removal of nutrient limitations by long-term fertilization decreases nocturnal water loss in savanna trees, Tree Physiol., 27, 551-559, doi:10.1093/treephys/27.4.551, 2007.

Sellers, P. J., Randall, D. A., Collatz, G. J., Berry, J. A., Field, C. B., Dazlich, D. A., Zhang, C., Collelo, G. D., and Bounoua, L.: A Revised Land Surface Parameterization (SiB2) for Atmospheric GCMS. Part I: Model Formulation, J. Climate, 9, 676-705, doi:10.1175/1520-0442(1996)009<0676:ARLSPF>2.0.CO;2, 1996.
Van Gorsel, E., Leuning, R., Cleugh, H. A., Keith, H., Kirschbaum, M. U. F., and Suni, T.: Application of an alternative method to derive reliable estimates of nighttime respiration from eddy covariance measurements in moderately complex topography, Agr. Forest Meteorol., 148, 1174-1180, doi:10.1016/j.agrformet.2008.01.015, 2008.

Wei, J. and Dirmeyer, P. A.: Dissecting soil moistureprecipitation coupling, Geophys. Res. Lett., 39, L19711, doi:10.1029/2012GL053038, 2012.

Welp, L. R., Keeling, R. F., Meijer, H. A. J., Bollenbacher, A. F., Piper, S. C., Yoshimura, K., Francey, R. J., Allison, C. E., and Wahlen, M.: Interannual variability in the oxygen isotopes of atmopsheric $\mathrm{CO}_{2}$ driven by El Nino, Nature, 477, 579-582, doi:10.1038/nature10421, 2011.

Zeppel, M. J. B., Lewis, J. D., Phillips, N. G., and Tissue, D. T.: Consequences of nocturnal water loss: a synthesis of regulating factors and implications for capacitance, embolism and use in models, Tree Physiol., 34, 1047-1055, doi:10.1093/treephys/tpu089, 2014. 